\title{
PROBLEM KEILMUAN PENDIDIKAN AGAMA ISLAM
}

\author{
M. Saekhan Muchith \\ STAIN Kudus, Jawa Tengah, Indonesia \\ muhsaekan@gmail.com
}

\begin{abstract}
THE SCIENTIFIC PROBLEM OF ISLAMIC EDUCATION. This paper aims to study the scientific problems of Islamic education. This is because the Islamic religious education (including the Islamic educational institutions such as STAIN, IAIN and UIN) is unique when compared to other sciences and institutions. The word "Islam" has its own characteristic which involves the science and the institution. Therefore, the science of Islamic education and Islamic education institutions must be able to carry out the vision of Islam as a religion of peace. Science of Islamic education and Islamic education institutions must be able to carry out the vision and mission of the Islamic religion in the context of ritual, muamalah or nationality. Consequently Islamic science must be able to formulate the structure and format of science that addresses the problems faced by Muslims. The slow quality of Islamic science and the quality of Islamic education institutions were triggered by problems called dichotomies science that exists only in debate. This leads to the less optimal performance of Islamic science, it is not directly able to formulate how this science is able to contribute to society. For the further implication, Islamic science became stagnant in the corridors of "science for science" and "discourse to discourse" that can only be read and debated.
\end{abstract}

Keywords: Islamic Education, Islamic Education Institution. 


\begin{abstract}
Abstrak
Tulisaan ini bertujuan untuk mengkaji problematika keilmuan pendidikan agama Islam. Ini karena pendidikan agama Islam (termasuk di dalamnya lembaga pendidikan Islam seperti STAIN, IAIN dan UIN) memiliki keunikan jike a dibanding dengan ilmu dan lembaga yang lain. Kata "Islam" memiliki karakter tersendiri yang memayungi ilmu dan lembaga tersebut. Oleh sebab itu, ilmu pendidikan Islam dan lembaga pendidikan Islam harus mampu menjalankan visi Islam sebagai agama kedamaian. Ilmu pendidikan Islam dan lembaga pendidikan Islam harus mampu menjalankan visi dan misi agama Islam baik dalam konteks ritual, muamalah maupun kebangsaan. Konsekuensinya ilmu Islam harus mampu merumuskan struktur dan format keilmuan yang mampu menjawab problematika umat Islam. Lambatnya mutu ilmu Islam dan kualitas lembaga pendidikan Islam, dipicu oleh problem yang bernama dikotomi ilmu yang banya ada dalam perdebatan. Hal itulah yang menyebabkan kinerja ilmu Islam tidak langsung merumuskan bagaimana ilmu mampu memberikan kontribusi kepada masyarakat. Implikasi selanjutnya bangunan ilmu Islam hanya berjalan dalam koridor dari ilmu untuk ilmu dan dari wacana untuk wacana.
\end{abstract}

Keywords: Pendidikan Agama Islam, Lembaga Pendidikan Islam

\title{
A. Pendahuluan
}

Lembaga pendidikan agama Islam pertama kali adalah dikenal dengan sebutan $A l$ Arqam yang didirikan oleh Rasulullah Muhamamd saw pada tahun 1 Hijriyah. Maksud dan tujuan pendirian al arqam adalah untuk melakukan pembelajaran dan pendidikan kepada umat Islam agar seluruh umat Islam memiliki kemampuan dalam menghadapi realitas kehidupan sosialnya. Nama al arqam diambil dari nama pemilik rumahnya yaitu Muhamamd Arqam bin Arqam yang memiliki komitmen tinggi dalam keimanan dan ketaqwaan.

Lembaga Pendidikan Agama Islam (LPAI) memiliki tugas sangat luas dan komprehensif jika dikaitkan dengan kepentingan atau kebutuhan umat Islam dalam kehidupan. LPAI memiliki tugas membimbing, mengarahkan, membina, dan memberdayakan 
semua potensi yang ada di dalam tubuh manusia agar mampu menyelesaikan semua problem kehidupan sosialnya. Setidaknya ada tiga potensi atau kecerdasan yang ada di dalam diri manusia yaitu Kecerdasan Intelektual (IQ,) Kecerdasan Emosional (EQ) dan Kecerdasan Spiritual (SQ). ${ }^{1}$

Pentingnya LPAI mengembangkan semua potensi atau kecerdasan dapat dilihat dari perjalanan sejarah bahwa materi yang diajarkan di dalam pendidikan al arqam tidak hanya menyangkut tentang tata cara baca tulis al-Quran dan tata cara beribadah, melainkan Rasulullah juga mengajarkan materi tentang berdagang (ekonomi), tentang cara menghadapi musuh (politik/tatanegara), tentang bagaimana menggunakan alat untuk berperang (teknologi), dan materi tentang bagaimana melakukan bergaulan dengan sesama manusia baik seagama maupun tidak seagama (sosiologi/psikologi). ${ }^{2}$

Dilihat dari makna kata "Islam", mengandung implikasi bahwa LPAI harus mampu melakukan penyadaran terhadap makna "Islam" secara utuh. Islam secara bahasa diartikan selamat, pasrah, patuh. Secara lebih luas, Islam dimaknai kepatuhan, keselamatan, kedamaian dan kepatuhan. Kepatuhan dan keselamatan serta ketaatan tidak hanya sebatas dalam hal norma agama melainkan menyangkut semua aspek kehidupan manusia. Artinya semua umat Islam harus memiliki kepatuhan dan kepasrahan serta kedamaian selama menjalani kehidupan. Hal ini sejalan dengan ajaran Islam dimana setiap umat Islam bertemu baik formal maupun Informal disunahkan (dianjurkan) mengucapkan "Assalamu'alaikum warohmatullah wabarokaatuh" yang mengandung arti doa agar kita semua selalu dalam kondisi selamat dan damai. ${ }^{3}$

${ }^{1}$ Taufiq Pasiak, Revolusi IQ/EQ/SQ antara Neurosains dan Al Quran, (Bandung: Mizan, 2002), hlm. 18.

${ }^{2}$ Musthafa Murad, Kisah Hidup Umar Ibn Khattab, (Jakarta: Zaman, 2007), hlm. 35 .

${ }^{3}$ Mohammad Daud Ali, Pendidikan Agama Islam, (Jakarta: PT Raja Grafindo Persada, 1998), hlm. 56. 
Islam dilihat dari aspek tujuan awalnya adalah sebagai agama Rabmatan lil'alamïn yaitu kemampuan Islam untuk mewujudkan kedamaian, kesejahteraan dan keamanan di dalam kehidupan manusia di dunia. Kesejahteraan dan kedamaian tidak terbatas hanya umat Islam saja, melainkan harus dapat dirasakan semua mahluk yang ada di dunia, yang meliputi manusia, binatang, tumbuhan, lautan, gunung, dan lain sebagainya. Artinya Islam hadir tidak hanya untuk memperbaiki internal maanusia, melainkan harus memperbaiki sikap dan kepribadian manusia yang terkait dengan dirinya sendiri, hubungan antar manusia dan hubungan manusia dengan lingkungan.

Pendidikan agama Islam berada di atas semua jenis pendidikan, karena Pendidikan Agama Islam memiliki sifat atau payung yaitu "Islam" yang secara otomatis membawahi semua aspek kehidupan maanusia. Konsekuensinya, LPAI tidak cukup hanya mengajarkan atau membimbing hal hal yang sifatnya normative keagamaan melainkan juga harus memberikan penyadaran semua problem kehidupan manusia dengan tidak meninggalkan nilai-nilai atau pesan yang ada di dalam agama Islam. Pertanyaaan selanjutnya, apa dan seperti apa struktur pendidikan agama Islam? Dan apa problem yang dialami pendidikan agama Islam jika dikaitkan dengan kebutuhan atau problem umat Islam di zaman sekarang?

\section{B. Pembahasan}

\section{Pendidikan Agama Islam}

Islam sangat menghargai orang yang berilmu atau berpengetahuan. Allah mengangkat derajat atau memberi kemuliaan kepada orang yang berilmu. Firman Allah swt yang artinya: "Niscaya Allah akan meninggikan orang orang yang berilmu pengetabuan beberapa derajat.” (Q. S. Al-Mujadalah (58): 11).

Ayat ini mengandung makna bahwa setiap umat Islam harus selalu mengembangkan ilmu pengetahuan secara terus 
menerus sehingga umat Islam memiliki derajat atau kemuliaan secara optimal. Para pemikir atau ilmuwan muslim berpendapat tentang pentingnya belajar atau mengembangkan ilmu pengetahuan sebagai berikut:

a. Ibn Abd al Barr: "Kamu akan menjadi orang yang pandai ('alim) selagi kamu menjadi pembelajar (muta'allim). Jikalau kamu tidak belajar lagi, maka pastilah kamu menjadi orang yang bodoh."

b. Imam Malik: "Tidak sepantasnya, bagi orang yang memiliki ilmu pengetahuan kemudian mereka berhenti melajar atau mengembangkan ilmu pengetahuan yang dimilikinya. Maka dia akan sia sia hidupnya.”

c. Abdullah Ibn al Mubarak: "Ketika ditanya: sampai kapan tuan harus belajar? Jawabnya" sampai mati, karena boleh jadi ada pengetahuan yang sangat penting di dunia ini yang belum sempat saya catat atau peroleh."

d. Abu Amr ibn 'Ala: "Kepadanya ditanya: sampai kapan seseorang sebaiknya belajar? Jawabnya: sampai kehidupan ini menjadi baik karena berkat kemajuan ilmu pengetahuan." (lebih lanjut baca: A Ilyas Ismail dalam buku True Islam)

Memahami apa itu pendidikan Agama Islam akan lebih jelas jika terlebih dahulu dilihat dari perspektif epistimologi. Secara umum epistimologi terdiri dari dua kata yaitu epestem yang berarti pengetahuan dan logos yang bermakna ilmu. Menurut bahasa Inggris epistimologi berarti theory of knowledge (teori tentang pengetahuan) sedangkan dalam bahasa Arab disebut dengan istilah nazhariyyat al ma'rifah (teori tentang pengetahuan). ${ }^{4}$

Terminologi tentang pendidikan atau pembelajaran menurut kaca mata Islam dimulai dari lima ayat pertama kali turun yang artinya: "Bacalah dengan menyebut nama tuhanmu yang menciptakan, Dia telah menciptakan manusia dari segumpal darah, Bacalah dan Tuhanmulab Yang Mahamulia, Yang mengajarkan manausia

${ }^{4}$ A Ilyas Ismail, True Islam, (Jakarta: Mitra Wcana Media, 2013), hlm. 32. 
dengan pena, Dia mengajarkan manusia apa yang tidak diketahui." (Q. S. Al-Alaq (96): 1-5).

Ayat tersebut mengandung pelajaran atau makna bahwa Allah memerintahkan kepada manusia membaca (mempelajari, meneliti, menganalisis dan lain sebagainya) dari apa saja yang diciptakan baik dari peristiwa yang tersurat (qauliyah) maupun realitas yang tersirat yaitu fenomena yang ada di dunia. Membaca atau mempelajari semua fenomen yang ada didunia ini harus diawali dari kesadaran adanya kehadiran sang pencipta (Tuhan), sehingga apa yang dipelajari selalu memperhatikan etika atau norma yang diatur dalam agama. (lebih detail baca Al-Quran dan tafsirnya : Kementerian Agama RI tahun 2012).

Profil manusia yang memiliki pengetahuan secara utuh disebut Ulama. Dalam firman-Nya dikatakan bahwa "Yang takut (lagi kagum) kepada Allah dari bamba hamba-Nya hanyalah para ulama" (QS. Fatir (35): 28).

Ulama disini tidak hanya dipahami profil manusia yang memahami pengetahuan atau informasi tentang norma agama (Quran dan hadis) dalam artian hanya orang yang mengetahui secara mendalam tentang baca, tulis, tafsir al Quran dan hadis, melainkan seseorang yang memiliki pengetahuan tentang berbagai fenomena yang ada di hamparan bumi atau jagat raya. Ulama adalah seseorang yang mengetahui secara mendalam tentang berbagai fenomena atau problem yang ada di alam raya ini. Ulama adalah sosok yang memiliki wawasan atau konsep tentang bagaimana pemahami realiats di alam raya, dan juga memiliki kemampuan mengambil hikmah dibalik realitas alam raya ini.

Pengajaran yang ada di sekolah-sekolah selama ini masih terkesan tidak memperhitungkan pentingnya pengajaran agama Islam, mereka lebih mengutamakan materi pembelajaran yang bersifat umum. Memang bukan tanpa alasan mereka menyampingkan akan pengajaran pendidikan Islam, pelajaran ini tidak begit diperhatikan mengingat perhatian dari pemerintah juga terllihat menyampingkan akan pentingnya mata pelajaran 
pendidikan agama Islam, terbukti yang dijadikan patokan dalam masuknya perguruan tinggi tidak termasuk pada pelajaran agama Islam.

Pendidikan termasuk di dalamnya peendidikan Islam memiliki ruang lingkup yang berbeda dengan ilmu lainnya. Dilihat dari tujuannya, pendidikan agama Islam memiliki makna yang sangat mendalam, yaitu untuk mengenal Sang Pencipta atau Allah swt dengan harapan tercapai kebahagiaan dan kesejahteraan kehidupan dunia dan akherat. Seperti yang dikutip oleh Naquib Al Attas: "The purpose for seeking knowledge in Islam is to inculcate goodness or justice in man as man and individual self. The aim of education in Islam is therefore to produce a good man... the fundamental element inherent in the Islam concept of education is the inculcation of adab."

Tujuan pendidikan agama Islam sangat luas dan memiliki makna sangat mendalam. Tujuan utamanya untuk melahirkan profil manusia yang ideal (baik) dan memiliki adab. Oleh sebab itu, tujuan pendidikan agama Islam tidak cukup hanya bersifat fisik dan non fisik, tetapi lebih dari itu adalah untuk penanaman kesadaran hakikat manusia untuk menyadari dari mana dia diciptakan, untuk apa dia dihidupkan dan dengan bagaimana dia mencapai kebahagiaan.

Obyek atau kajian pendidikan agama Islam memiliki perbedaan dengan pendidikan selain PAI. Pendidikan atau pengetahuan Barat berasal dari falsafah atau cara fikir Aristoteles, bahwa ilmu pengetahuan itu bersumber dari empiris dan rasio (akal). Kebenaran adalah apa yang dapat dilihat dan sesuai dengan rasio manusia. Aristoteles memiliki prinsip "Nihil est in intellectu Nisi Prius In Sense", artinya tidak ada sesuatu yang ada di akal manusia selain yang terlebih dahulu diindera atau dilihat atau dirasakan". (Dony Gaharal dalam Pemikiran Aristoteles).

Obyek kajian Pendidikan Islam adalah apa yang dilihat/ dirasakan (empiris), apa yang dapat di rasio dan apa yang diyakini. Obyek pendidikan Islam minimal ada tiga hal yaitu akal, empiris dan keyakinan. Ada tiga hal atau potensi yang dimiliki setiap 
manusia dan potesi itu akan bisa dikembangkan untuk mewujudkn kualitas kehidupan manusia. Tiga hal atau potensi itu adalah (a) nafsu: yang mengarah kepada jiwa atau semangat manusua untuk mencari keuntungan (b) Akal rasio: akan mengarah kepada karakter atau semangat untuk melahirkan jiwa kebijaksanaan atau kedewasaan. (c) Jiwa/roh/keyakinan: akan mengarah kepada kehormatan bagi manausia. Pendidikan Agama Islam mengarahkan kepada tiga hal ini dan berusaha secara optimal untuk mengoptimalkan rasio dan jiwa atau roh, sehingga manusia atau umat Islam memiliki kebijaksanaan dan kehormatan secara maksimal. Inilah letak perbedaannya pendidikan agama Islam dengan ilmu lainnya.

Metode pendidikan agama Islam sedikitnya ada tiga macam yaitu; pertama, metode bayani, yaitu metode berfikir atau pengembangan ilmu yang bersifat tekstualis. Kedua, metode Irfani, yaitu cara berfikir atau pengembangan ilmu pengetahuan yang didasarkan kepada intuisi atau spiritual. Ketiga, Burhani yaitu cara pengembangan ilmu pengetahuan yang didasarkan kepada kekuatan akal pikiran atau rasional. ${ }^{5}$

Islam memiliki dua aspek yang tidak boleh ditinggalkan satu dengan lainnya. Islam ibarat memiliki dua sisi mata logam yaitu satu sisi aspek ta'abudi (keyakinan) dan satu aspek ta'aquli (akal rasional). Artinya Islam memerlukan optimalisasi keyakinan dan juga optimalisasi kerja akal pikiran. Islam akan dapat memberikan kontribusi besar kepada umat Islam jika dijelaskan dari aspek keyakinan dan rasio. Hal ini berimplikasi kepada ilmu PAI yang harus mampu memberikan kemampuan dan pemahaman keadaan umat Islam umumnya dan peserta didik khususnya agar memiliki kesadaran untuk menggunakan keyakinan dan pikirannya dalam menjelaskan berbagai persoalan kehidupan manusia.

${ }^{5}$ Amin Abdullah, Desain Pengembangan Akademik I AIN Menuju UIN Sunan Kalijaga : Dari Pendekatan Dikhotomik-Atomistik ke arah integrative Multidiciplinary, (Bandung: Mizan, 2005), hlm. 56. 
Pendidikan Agama Islam akan melahirkan lulusan yang optimal jika metode pengembangan ilmu tersebut dilakukan secara optimal dan dilakukan secara komprehensif, artinya ketiga metode tersebut haraus dilakukan secara komplemnter atau saling melengkapi. Jika hanya menggunakan cara fikir bayani, maka akan melahirkan manusia yang normative atau tekstualis, jika hanya menggunakan metode irfani, maka bukan tidak mungkin akan melahiran sosok manusia yang fatalistik dan jika hanya menggunakan metode burhani bukan tidak mungkin akan melahirkan manusia yang sekuler. Idealisme pendidikan Islam harus menggunakan ketiga cara yang dilakukan secara proporsional dan optimal.

Sampai di sini, jelas bahwa pendidikan Islam tidak bisa diartikan pendidikan yang mengajarkan Islam secara formal ritual atau normatif saja seperti materi tentang baca tulis Alquran, tata cara sholat, syarat rukun sholat, puasa, zakat, haji, umroh, iman kepada Allah, iman kepada Rasulullah. Pendidikan Islam adalah materi yang berkaitan dengan pengetahuan, etika manusia dalam menghadapi problem kehidupan di dunia dan akherat. Pendidikan agama Islam adalah memuat materi yang mengajarkan tentang tata cara bagaimana agar manusia mampu mencapai kebahagiaan di dunia dan akherat.

Pendidikan Agama Islam meliputi semua pengetahuan, pengalaman dan realitas yang terjadi di alam raya ini, mulai dari bagaimana memahami atau memaknai, sampai bagaimana memfungsikan apa yang ada di bumi ini untuk kemashlahatan atau kemanfaatan bagi manusia. Pendidikan agama Islam berada di atas pendidikan lainnya, karena pendidikan Islam mewarnai, mengilhami atau memberi inspirasi ilmu-ilmu lainnya seperti ilmu sosiologi, psikologi, manajemen, kewarganegaraan, kependudukan, politik, fisika, biologi, matematika, musik, olahraga dan lainnya. 


\section{Problem Keilmuan}

Secara umum problem diartikan adanya kesenjangan atau perbedaan antara apa yang diidealkan (diinginkan) dengan apa yang dirasakan (dialami). Problem tidak selamanya bersifat negative dan problem tidak semua destruktif. Problem merupakan sebuah keniscayaan bagi setiap manusia yang hidup di dunia. Problem ada yang menyamakan dengan konflik, sehingga lahir sebuah teori atau manajemen yang disebut teori konflik atau manajemen konflik.

Lawan dari teori konfik adalah teori struktural fungsional. Kedua teori tersebut memiliki cara pandang berlawanan dalam memahami eksistensi atau karakter manusia. Teori konflik memandang bahwa manusia memiliki kecenderungan melakukan kesalahan atau pelanggaran sehingga berimplikasi kepada pentingnya menyusun aturan atau norma untuk mengikat sikap dan perilaku manusia. Sementara teori struktural fungsional memandang manusia pada hakikatnya ingin berbuat jujur, baik, lurus dan tidak melanggar. Oleh sebab itu, aturan atau regulasi yang ada hanya untuk mengikat dan memaksa manusia sehingga tidak akan menimbulkan sikap dan perilaku yang menyimpang.

Problem keilmuan juga bisa disandingkan dengan konflik keilmuan. PAI dari aspek keilmuan memiliki keunikan yang harus dijelaskan kepada publik. Dimanapun eksistensi PAI pertama dan utama dipertanyakan adalah tentang aspek dikotomi keilmuan. Sampai hari ini, persoalan dikotomi ilmu masih menjadi perdebatan panjang yang belum mencapai ujung kesepakatannya. Menurut penulis, persoalan dikotomi ilmu dalam Islam tidak akan pernah selesai atau mencapai kesepakatan. Pendidikan Islam akan selalu di"gugat" tentang dikotomi, hal ini akan sangat terlihat pada saat lembaga pendidikan agama Islam semacam STAIN, IAIN dan UIN mengajukan gagasan atau program studi baru tentang manajemen pendidikan, ekonomi Islam, politik Islam, selalu dipertanyakan apa perbedaan program studi yang akan 
diajukan di STAIN, IAIN dan UIN dibanding dengan universitas umum semacam UI, UGM atau UNDIP.

Pertanyaan itu menjadi wajar, karena program studi itu ada di bawah naungan lembaga yang berlabel Islam. Pertanyaan selanjutnya, apakah apa yang dikelola lembaga pendidikan Islam semacam STAIN, IAIN dan UIN harus memiliki perbedaan secara diametral dengan lembaga pendidikan di luar STAIN, IAIN dan UIN?. Perdebatan tentang dikotomi yang merupakan problem utama pendidikan agama Islam ini, menjadi aspek terhambatnya perkembangan lembaga dan keilmuan Islam, karena setiap kebijakan di bawah naungan lembaga pendidikan semacam STAIN, IAIN dan UIN tidak bisa langsung bekerja secara optimal, melainkan terlebih dahulu ada semacam "pemanasan" atau perdebatan seperti apa postur, format dan perbedaan dengan ilmu di luar STAIN, IAIN dan UIN. Lebih parah lagi, semakin asyiknya perdebatan itu, akhirnya lembaga pendidikan Islam hanya melahirkan hasil perdebatan atau biasa dikenal "sepakat dalam perbedaan".

Diakui atau tidak problem epistimologi atau dikotomi itu secara langsung maupun tidak langsung menyebabkan lambatnya kinerja ilmu keislaman dalam melakukan respon problem kehidupan masyarakat. Implikasinya ada kesan ilmu- ilmu pendidikan agama Islam hanya melahirkan wacana dan wacana "dari ilmu ke ilmu" atau science to science. Ilmu Pendidikan Agama Islam belum mampu melahirkan karya yang mampu memberikan kontribusi nyata dalam kehidupan masyarakat. Belum mampu memiliki paradigma dari ilmu ke masyarakat (Science to society). Islam seakan belum berdaya jika dihadapkan pada berbagai problem kebangsaan, seperti bagaimana Islam menjawab tantangan kebangsaan seperti maraknya korupsi, maraknya dekadensi moral di tengah masyarakat, mudahnya terjadi tawuran antarkelompok.

Persoalan-persoalan yang jelas-jelas menyangkut tentang perintah agama Islam saja belum mampu dioptimalkan atau dijawab, seperti bagaimana rumusan keilmuan untuk mengelola 
pengoptimalan pengelolaan shodaqah, zakat yang dikeluarkan secara rutin oleh umat Islam, bagaimana rumusan keilmuan implementasi pajak dan zakat, umat Islam yang sudah membayar pajak secara otomatis dianggap sudah mengeluarkan zakat atau belum, bagaimana format atau struktur keilmuan yang tepat yang mampu mempengaruhi sikap dan kesadaran umat islam secara optimal dalam menyesuaikan antara kesadaran pengetahuan, kesadaran keyakinan dan kesadaran melaksanakan atau menjalankan.

Problem lain yang dialami oleh umat Islam adalah problem kultural yaitu belum adanya kesadaran yang dapat dilaksanakan secara optimal. Manusia setidaknaya memiliki tiga kesadaran, yaitu (a) kesadaran untuk mengetahui (b) kesadaran untuk meyakini dan (c) kesadaran untuk melaksanakan atau menjalankan.

Setiap umat Islam jika ditanya apakah mengetahui bahwa Islam mengajarkan menjaga lingkungan dan kebersihan, pasti jawabnya mengetahui. Jika ditanya lagi apakah meyakini bahwa manusia yang merusak lingkungan, dan tidak menjaga kebersihan itu termasuk melanggar perintah agama, pasti jawabnya juga meyakini. Umat Islam memiliki kesadaran meengetahui dan kesadaran meyakini tentang pentingnya melestarikan lingkungan dan menjaga kebersihan, namun mengapa umat Islam belum mampu melaksanakan apa yang diketahui dan diyakini. Umat Islam tanpa berdosa melakukan perusakan lingkungan dan membuang sampah sembarangan. Di negara-negara yang penduduknya mayoritas Islam, justru kerusakan lingkungan sangat besar, sementara di negara-negara yang penduduknya mayoritas tidak beragama Islam malah relatif kecil kerusakan lingkungan dan termasuk kebersihan lingkungannya.

Persoalan politik atau tatanan pemerintahan di berbagai negara yang penduduknya beragama Islam juga masih belum mapan atau sering dilanda konflik politik yang berkepanjangan, seperti negara-negara di Timur Tengah yang sampai sekarang belum mampu menyusun konsep pengelolaan negara secara tepat 
dan memberi kemaslahatan bagi warganya. Negara-negara Barat yang tidak memiliki keyakinan kepada Alquran dan hadis justru tata kehidupan politik kenegaraannya relatif lebih baik dibanding negara-negara yang penduduknya mayoritas beragama Islam.

Islam belum mampu merumuskan postur keilmuan yang bisa menjawab problem tersebut. Hal ini disebabkan oleh salah satu aspek yaitu karena lembaga pendidikan Islam atau ilmu agama Islam terlalu sibuk melakukan perdebatan epistimologis sehingga tidak optimal dalam melakukan rumusan ilmu yang memiliki manfaat untuk umat Islam khususnya dan masyarakat pada umumnya. Problem epistimologi di lingkungan pendidikan Islam merupakan sebuah keniscayaan, tidak mungkin dihilangkan namun juga jangan sampai terlalu disibukkan dengan perdebatan epistimologi dan dikotomi.

\section{Simpulan}

Problem keilmuan berupa epistimologi atau dikotomi di dalam lingkungan pendidikan Islam atau lembaga pendidikan Islam semacam STAIN, IAIN dan UIN merupakan problem yang selain dikatakan problem keilmuan juga dapat dikatakan sebagai problem kultural. Artinya, problem tersebut tidak mungkin dihilangkan karena ini menyangkut karakteristik kelembagaan dan keilmuan. Meskipun demikian, problem dikotomi jangan sampai menjadi perdebatan terlalu panjang sehingga Islam tidak optimal menjalankan peran dan fungsinya sebagai agama rahmatan ll'alamiin. 


\section{DAFTAR PUSTAKA}

Abdullah, Amin, Desain Pengembangan Akademik LAIN Menuju UIN Sunan Kalijaga: Dari Pendekatan Dikhotomik-Atomistik ke arah integrative Multidiciplinary, Bandung: Mizan, 2005.

Adian, Dony Gahral, Pemikiran Aristoteles, Jakarta: Poliyama Widyapustaka, 2003.

Al-Attas, Muh Naquib, Islam and Secularism, Malaysia: ISTAC, 2003.

Ali, Mohamamd Daud, Pendidikan Agama Islam, Jakarta: PT. Raja Grafindo Persada, 1998.

Departemen Agama RI, Alquran dan Terjemahnya, Jakarta: Departemen Agama Republik Indonesia, 2004.

Husain, Adian, Filsafat Ilmu: Perspektif Barat dan Islam, Depok Jawa Barat: Gema Insani, 2013.

Ismail, A.Ilyas True Islam, Moral, Intelektual, Spiritual, Jakarta: Mitra Wacana Media, 2013.

Kementerian Agama RI, Al Quran dan Tafsirnya, Jakarta: Kementerian Agama Republik Indonesia, 2012.

Murad, Musthafa, Kisah Hidup Umar Ibn Khattab, Jakarta: Zaman, 2007.

Pasiak, Taufiq, Revolusi IQ/EQ/SQ antara Neurosains dan Al Quran, Bandung: Mizan, 2005.

Rahardjo, Dawam, Kritik Nalar Islamisme dan Kebangkitan Islam, Jakarta: Freedom Institute, 2012.

Shihab, M. Quraish, Dia Dimana mana, "Tangan" Tuhan di balik Setiap Fenomena, Tangerang: Lentera hati, 2012.

Sulasman \& Dadan Rusmana, Filsafat Sosial Budaya di Dunia Islam, Bandung: Pustaka Setia, 2014.

Yahya, Syarif, Kampus Pintar Agama Islam, Bandung: Nuansa Cendekia, 2014. 